\title{
The use of semi-quantitative tests at Cesarean section delivery for the differentiation of canine fetal fluids from maternal urine on the basis of biochemical characteristics
}

\author{
Balogh, Orsolya ; Roch, Marie ; Keller, Stefanie ; Michel, Erika ; Reichler, Iris M
}

\begin{abstract}
In dogs, there is no diagnostic test to identify and differentiate fetal fluids from maternal urine in the event that a clear-yellowish vulvar discharge is observed pre-whelping. The objective of this study was to find a test that could easily and accurately identify rupture of the fetal membranes preceding parturition. Maternal urine, and amniotic fluid (AMF) and allantoic fluid (ALF) from only one fetus per bitch, were collected intraoperatively during Cesarean section. Specific gravity (SG) was analyzed with a refractometer, whereas the presence of leukocytes, protein, glucose, ketones, bilirubin, urobilinogen, nitrite, erythrocyte/hemoglobin ( $\mathrm{Hb}$ ), and the $\mathrm{pH}$ were assessed using a urine dipstick (Combur-Test ${ }^{\circledR}$ ). Combined calcium and magnesium $(\mathrm{Ca} / \mathrm{Mg})$ content were evaluated with the Total Hardness Test. The AmniSure test, which detects rupture of fetal membranes in women on the basis of the presence of human placental alpha microglobulin-1, was also performed on canine AMF, ALF, and urine. Data were analyzed using the Fisher's exact test, Wilcoxon signed-rank test, and Pearson's correlation. Sensitivity, specificity, and positive and negative likelihood ratios (LR) were calculated for parameters with significant difference between urine and both fetal fluids. Maternal urine had higher SG and lower leukocyte, protein, Hb, and $\mathrm{Ca} / \mathrm{Mg}$ content than AMF and ALF. Glucose was more often present in AMF $(\mathrm{n}=17)$ and ALF (n $=12$ ) than in urine $(\mathrm{n}=1)$, whereas ketone bodies were rarely detected in ALF compared with urine. Bilirubin content was higher in urine and ALF than in AMF. AMF pH was less variable and higher than the $\mathrm{pH}$ of ALF or urine. The AmniSure was negative in all samples tested. Sensitivity and specificity for SG and for the detection of leukocytes, protein, glucose, $\mathrm{Hb}, \mathrm{Ca} / \mathrm{Mg}$, and glucose without ketones in urine and fetal fluids were between $42 \%$ to $100 \%$ and $65 \%$ to $100 \%$, respectively. Best positive LR was achieved for the detection of glucose without ketones and best negative LR for SG of 1.022 or less. In conclusion, the AmniSure test, which is used in humans with high diagnostic accuracy, cannot identify AMF and ALF in dogs. On the basis of our results in 26 dogs undergoing Cesarean section, the presence or absence of fetal fluids could be best determined by a positive glucose test without ketone bodies or by SG higher than 1.022, respectively. These tests may serve as additional tools to recognize parturition if clear-yellowish vulvar discharge is present in a term pregnant bitch, but their accuracy and practicability in the clinical setting need to be confirmed.
\end{abstract}

DOI: https://doi.org/10.1016/j.theriogenology.2016.09.024

Posted at the Zurich Open Repository and Archive, University of Zurich ZORA URL: https://doi.org/10.5167/uzh-130017

Journal Article

Accepted Version 
The following work is licensed under a Creative Commons: Attribution-NonCommercial-NoDerivatives 4.0 International (CC BY-NC-ND 4.0) License.

Originally published at:

Balogh, Orsolya; Roch, Marie; Keller, Stefanie; Michel, Erika; Reichler, Iris M (2017). The use of semiquantitative tests at Cesarean section delivery for the differentiation of canine fetal fluids from maternal urine on the basis of biochemical characteristics. Theriogenology, 88:174-182.

DOI: https://doi.org/10.1016/j.theriogenology.2016.09.024 
1 The use of semi-quantitative tests at Cesarean section delivery for the differentiation of

2 canine fetal fluids from maternal urine based on biochemical characteristics

3

4 Orsolya Balogh*, Marie Roch, Stefanie Keller, Erika Michel, Iris Margaret Reichler

5

6 Clinic of Reproductive Medicine, Vetsuisse-Faculty, University of Zurich, Zurich,

7 Switzerland

8

$9 *$ Corresponding author

10

11

12 Contact details of corresponding author:

13 Orsolya Balogh

14 Clinic of Reproductive Medicine, Vetsuisse-Faculty

15 University of Zurich

16 Winterthurerstrasse 260

178057 Zurich

18 Switzerland

19 E-mail: obalogh@vetclinics.uzh.ch

20 Phone: $+41 / 446358267$

21

22

23

24

25

26 
50 best negative $\mathrm{LR}$ for $\mathrm{SG} \leq 1.022$. In conclusion, the AmniSure ${ }^{\circledR}$ Test, which is used in humans

51 with high diagnostic accuracy, cannot identify AMF and ALF in dogs. Based on our results in

5226 dogs undergoing Cesarean section, the presence or absence of fetal fluids could be best

53 determined by a positive glucose test without ketone bodies or by SG > 1.022, respectively. 
54 These tests may serve as additional tools to recognize parturition if clear-yellowish vulvar 55 discharge is present in a term pregnant bitch, but their accuracy and practicability in the 56 clinical setting need to be confirmed.

57

58 Keywords: dog, pregnancy, amnion, allantois, parturition 
60 When a pregnant bitch is presented for leakage of variable amounts of watery, clear or

61 yellowish fluid from the vulva, there is no quick diagnostic test to help determine whether it is

62 composed of fetal allantoic fluid (ALF) and/or amniotic fluid (AMF), or it is maternal urine.

63 Urination may occur more frequently in bitches near the end of gestation due to the increased

64 size of the uterus pressing on the bladder and may sometimes be mistaken with leakage of

65 fetal fluids [1]. Rupture of the allantochorionic membrane (outer fetal membrane) as the fetus

66 enters the birth canal and leakage of the transparent, yellowish allantoic fluid is normal during

67 second stage labor $[1,2]$. However, when passage of ALF/AMF occurs before the birth of the

68 first pup without other signs of second stage labor (i.e. visible abdominal contractions) it is a

69 sign of dystocia. This may happen in cases of primary uterine inertia, that is, when uterine

70 contractions are completely lacking or too weak for fetal expulsion [1]. In the bitch, uterine

71 inertia accounted for $14 \%$ to $49 \%$ of dystocia cases [3, 4], or even up to $60 \%$ in predisposed

72 breeds like the Boxer [5]. Fast recognition and appropriate therapy are required to avoid

73 neonatal loss. To date, there is no tool for diagnosing rupture of the fetal membranes in dogs,

74 while a rapid test exists for women. The AmniSure ${ }^{\circledR}$ Test (AmniSure GmbH, Wetzlar,

75 Germany) is based on the detection of placental $\alpha$-microglobulin-1 (PAMG-1), as this protein

76 is present in higher concentrations in AMF compared to other biological fluids [6, 7] and is

77 used as a biomarker [8, 9]. Even small amounts of AMF can accurately be detected in vaginal

78 fluids with the AmniSure ${ }^{\circledR}$ Test, and it appears that artifacts from blood contamination do not

79 significantly interfere with the test's performance [10]. No AMF or ALF-specific proteins

80 have been identified for dogs, and the AmniSure ${ }^{\circledR}$ Test has not been evaluated on canine fetal

81 fluids.

$82 \mathrm{AMF}$ and ALF are produced by various mechanisms: i.e. secretions from the fetus,

83 transudation through the fetal skin before keratinization, or placental, trans- and

84 intramembranous pathways [11-18]. The biochemical characteristics and pregnancy stage-

85 related changes of fetal fluids were already described in women and in several domestic 
animal species. In cats, detailed information on fetal fluid composition (e.g. electrolytes,

87 proteins, glucose, enzymes of the liver, kidney and pancreas) and its time-dependent evolution

88 was compared to maternal blood but not to maternal urine [19]. In that study, several

89 parameters changed throughout gestation corresponding to the actual degree of fetal

90 development; moreover, changes in fetal fluid composition diverged from those in maternal

91 serum, which underscores the active contribution of the fetus to AMF and ALF production. In

92 dogs, such detailed analysis of fetal fluid composition is missing. Aralla and coworkers [20]

93 found decreased sodium levels in AMF in late- compared to mid-pregnant bitches, while AMF

94 osmolality, urea, total protein and potassium content were similar between the two time

95 points. An immunoprotective role of AMF and ALF was hypothesized after finding lysozyme

96 and immunoglobulin $\mathrm{G}(\mathrm{IgG})$ in canine fetal fluids [21]. Another recent study described the

97 presence of insulin-like growth factor 1 (IGF1) and non-esterified fatty acids (NEFA) in the

98 fetal fluids of term pregnant bitches and found that both NEFA and IGF1 concentrations were

99 dependent on the size of the dam [22]. In contrast, AMF glucose, lactate and cortisol levels

100 were not related to breed size, but differences in the values of these parameters were found

101 between puppies of bitches undergoing vaginal parturition or Cesarean section (C-section),

102 and also varied in cases of stillbirth [23]. We hypothesize that the composition of fetal fluids

103 in dogs differs not only from maternal serum but also from urine. The objective of our study

104 was to distinguish fetal AMF and ALF from maternal urine based on biochemical 105 characteristics using semi-quantitative tests at the time of C-section delivery.

\section{2. Material and methods}

$108 \quad 2.1$ Animals

109 Twenty-six bitches undergoing elective or emergency $\mathrm{C}$-section at the small animal clinic of 110 the Vetsuisse-Faculty, University of Zurich were included in the study. Informed consent was 111 obtained from the owners and the study was approved by the Cantonal Veterinary Authority of 112 Zurich (permit no. 04/2013). 
113 Elective C-sections were carried out in term pregnant dogs with high risk for dystocia.

114 Determination of term gestation was based on a combination of several diagnostic methods.

115 Ovulation was determined by serum progesterone (P4) levels during estrus (P4 $\geq 5 \mathrm{ng} / \mathrm{mL}$ at 116 ovulation, [24]). Additionally, and especially if the date of ovulation was unknown, the

117 prepartum P4 profile was followed to estimate the expected time of parturition [25].

118 Ultrasonography was carried out in all cases to determine gestational age by measuring

119 fetal biparietal diameter, to visualize intestinal peristalsis as an indicator of fetal maturity

120 and to evaluate fetal well-being (heart rate, movements) [26]. C-section was performed only when the bitch was near term (at least 61 days from ovulation or $<2$ days before the expected time of parturition) based on the combined results of the methods above.

\subsection{Collection and testing of fetal fluids and maternal urine}

During C-section, ALF and AMF (1-5 mL) were collected separately from the fetus nearest to the site of hysterotomy. The non-villous allantochorionic membrane was visualized and a small hole was made on it to allow placing a sterile syringe tip into the cavity. The ALF was then aspirated under visual control. Afterwards, the allantochorionic membrane was torn, the fetus in the intact amniotic membrane was visualized and the AMF was aspirated. Only one fetus per bitch was sampled not to prolong time needed to deliver all pups in the litter. This was crucial, as our study population included not only elective but emergency C-sections, where fetal stress may be more pronounced, and the clinical condition of the pups and dams may be compromised compared to elective surgeries. Maternal urine $(2-5 \mathrm{~mL})$ was obtained during surgery by cystocentesis after all puppies were delivered. Fluid samples were decanted in a urine collection tube without preservatives and kept at $+4{ }^{\circ} \mathrm{C}$ until analysis. All tests were carried out within 1 hour of collection.

Specific gravity $(S G)$ : Specific gravity of urine, AMF and ALF was analyzed with a manual refractometer (ATAGO Co., Ltd, Tokyo, Japan). A drop of fluid was placed on the 
refractometer glass and results were read on the appropriate scale (measurement range 1.000$1.050)$.

Urine colorimetric dipstick test: the Combur-Test ${ }^{\circledR}$ strips $\left({ }^{(} 2010\right.$ Roche, Roche Diagnostics Ltd., Rotkreuz, Switzerland) were used on maternal urine and fetal AMF and ALF for comparison among the fluid types. The parameters tested were $\mathrm{pH}$, leukocytes, nitrite, protein, glucose, ketones, urobilinogen (UBG), bilirubin and erythrocyte/hemoglobin ( $\mathrm{Hb})$ content. All reaction zones of the test strip were covered with urine, AMF or ALF, and the excess fluid was removed. Results were read after 1 minute by visual inspection. The color reaction of the test pad was compared to the color scale on the label and a value was assigned accordingly. Values of the color scale for each parameter as described on the test label are presented in Table 1. However, when the reaction could not be clearly assigned to one of the neighboring color blocks on the label, we recorded it as $0.5+$ above the lower value (e.g. $0.5+, 1.5+$, etc.). Negative or normal was recorded as 0 .

Calcium (Ca) and magnesium (Mg) concentration: the Total Hardness Test (MQuant ${ }^{\mathrm{TM}}$ Total Hardness Test 1.10046.0001, Merck KGaA, Darmstadt, Germany), which was originally developed to measure the hardness of water, was performed on urine, AMF and ALF samples. All five test pads of the strip were covered and then the excess fluid was removed. Results were read after 1 minute by visual inspection and comparing discoloration of the reaction zones to the color scale on the label. Depending on the number of pads on the test strip that turned from green to purple, the following values were available corresponding to a combined $\mathrm{Ca}$ and $\mathrm{Mg}$ content expressed as $\mathrm{CaCO}_{3}$ : negative, $1+(>90 \mathrm{mg} / \mathrm{L}), 2+(>180 \mathrm{mg} / \mathrm{L}), 3+(>270$ $\mathrm{mg} / \mathrm{L}), 4+(>360 \mathrm{mg} / \mathrm{L})$ and $5+(>450 \mathrm{mg} / \mathrm{L})$. When the color change of a reaction zone was not complete but at least half of the reaction pad was discolored, the result was read as $0.5+$ added to the number of fully discolored pads (e.g. $0.5+, 1.5+$, etc.). When only the edge or less than half of the reaction pad was discolored, it was interpreted as a negative reaction zone. 
167 (AmniSure GmbH, Wetzlar, Germany), which is a one-step immunochromatographic assay,

168 was performed on maternal urine, AMF and ALF. Samples with macroscopic blood 169 contamination were also used, as it seems that blood does not interfere with the test results 170 [10]. The test procedure and reading of results was carried out according to the

171 manufacturer's instructions (www.amnisure.com), except that the sterile swab provided to

172 collect the sample from the vagina in women was dipped for $1 \mathrm{~min}$ into the collection tube

173 containing either urine or one of the fetal fluids. When reading the results, the presence of 174 only one line (control line) should indicate a negative test, while two lines correspond to a 175 positive result. If no line is visible, the test is invalid and should be repeated.

\section{$177 \quad 2.3$ Statistical analysis}

178 To compare the frequency of the Combur-Test ${ }^{\circledR}$ and Total Hardness Test categories between 179 urine, AMF and ALF, the Fisher's exact test using a 2 by 2 contingency table was performed. 180 We classified the Combur-Test ${ }^{\circledR}$ results of leukocytes, glucose, ketone bodies, bilirubin and 181 nitrite into two categories: negative/normal $(0)$ or positive $(0.5+$ to $3+/ 4+)$. The results on 182 protein and erythrocyte/Hb were categorized into low and high: 0 to $1+($ low $)$ and $1.5+$ to $3+$ 183 (high) for protein, and 0 to $2.5+$ (low) and $3+$ to $4+$ (high) for erythrocytes/Hb. The Total Hardness Test result on $\mathrm{Ca} / \mathrm{Mg}$ content was also classified into low ( 0 to $3.5+$ ) and high (4+ to $5+$ ) categories. Specific gravity and $\mathrm{pH}$ were analysed by the Wilcoxon signed-rank test with Bonferroni correction in pairwise comparisons. Pearson's correlation was also used for SG. Only samples without macroscopic blood contamination were included in the statistical evaluation. All analyses were performed using SPSS 22.0 software (SPSS Inc., Chicago, IL). Significance was set at $\mathrm{P} \leq 0.05$ for the Fisher's exact test and for Pearson's correlation, and at $\mathrm{P} \leq 0.0167$ for the Wilcoxon signed-rank test after Bonferroni adjustment.

191 For parameters which differed significantly between urine and both fetal fluids, sensitivity 192 (SEN), specificity (SPC), positive and negative likelihood ratios (LR) were determined after 
setting the threshold at the same cut-off value that was used for the categories of the Fisher's

194

195

196

197

198

199

200

201

202

203

204

205

206

207

208

209

210

211

212

213

214

215

216 217 recommended for their age [27].

218 Characteristics of the dams and their pups, from which fetal fluids were collected, are 219 presented in Table 2.

exact test, and at $\leq 1.022$ for SG. Sensitivity (\%) was calculated using the formula SEN = true positive samples/(true positive samples + false negative samples)*100, specificity (\%) was determined as SPC $=$ true negative samples/(true negative samples + false positive samples)*100. Positive and negative LR were calculated as SEN/(1-SPC) and (1-SEN)/SPC, respectively. In the equation of the positive LR, 1 was replaced by 0.99 for SPC. If only one of the fetal fluid pairs (AMF or ALF) was available, then that result was used for the calculation. If both AMF and ALF samples were available but the results of the two differed as being true positive or false negative, always the false negative result was used. The same calculations were performed for specific combinations of parameters to increase the value of the diagnostic test.

\section{Results}

\subsection{Animals}

Emergency C-section was performed in $17 \mathrm{dogs}$ due to dystocia. Nine bitches underwent elective C-section because of high risk for dystocia due to singleton fetus $(n=2)$, breed predisposition ( $\mathrm{n}=6$, English and French Bulldogs, Chihuahua and Maltese breeds) and old age of a primiparous bitch $(n=1)$. Altogether, 100 puppies were delivered by C-section. However, only one fetus per dam was sampled for AMF and ALF adding up to a total of 26 fetuses. Three of those 26 puppies died within two hours after birth despite intensive resuscitation, and a fourth pup had a mild form of anasarca. The other puppies in the study $(n=22)$ were judged healthy, as they were successfully resuscitated, had no gross congenital malformations, nursed colostrum by themselves from the mother soon after C-section, and they kept their body temperature above $35.5{ }^{\circ} \mathrm{C}$ in an environmental temperature 
221

222

223

224

225

226

227

228

229

231

232 233

234

235

236

237

238

239

241

242

\subsection{Fluid samples}

As stated, we took AMF and ALF from only one fetus per bitch. The amount of urine and AMF collected was sufficient to perform all planned tests in all animals $(n=26)$. However, ALF could only be taken from 24 fetuses, and the amount was insufficient in two of these 24 samples to perform the Combur-Test ${ }^{\circledR}$. Slight macroscopic blood contamination occurred in the samples of 6 fetuses, i.e. in 3 ALF and 3 AMF, so they were excluded from the statistical analysis. Overall, maternal urine and fetal AMF was available from 23 bitch-fetus pairs for statistical comparison. Statistical analysis of SG and the Total Hardness Test was performed on maternal urine and fetal ALF in 21 bitch-fetus pairs, while comparison of the ComburTest $^{\circledR}$ results of maternal urine and the corresponding fetal ALF was possible in 19 bitch-fetus pairs. AMF and ALF were compared for SG and the Total Hardness Test in 18 fetuses, while the Combur-Test ${ }^{\circledR}$ comparison of AMF and ALF was possible in only 16 fetuses.

\subsection{Fetal fluids compared to maternal urine}

Specific gravity was lower in AM and AL than in maternal urine $(\mathrm{P}<0.001$ and $\mathrm{P}=0.003$, respectively; Figure 1). There was no correlation between $\mathrm{SG}$ of urine and AM or AL (P $\geq$ $0.190)$.

The Combur-Test ${ }^{\circledR}$ was used to compare maternal urine and fetal fluids for the presence of leukocytes, erythrocyte/Hb, protein, $\mathrm{pH}$, glucose, ketones, bilirubin, nitrite and UBG. Leukocytes were detected in several AMF $(n=11)$ and ALF $(n=10)$ samples, but only in one urine sample $(\mathrm{P}=0.001$ and $\mathrm{P}<0.001$, respectively; Figure $2 \mathrm{~A})$. Erythrocyte/Hb content was higher in AMF and ALF than in maternal urine $(\mathrm{P}<0.001$ and $\mathrm{P}<0.001$, respectively; Figure 2B). Similarly, high protein content $(>1+)$ was found in most fetal fluids, but only in one urine sample $(\mathrm{P}<0.001$ and $\mathrm{P}<0.001$, respectively; Figure $2 \mathrm{C})$. The $\mathrm{pH}$ was higher in AMF than maternal urine $(\mathrm{P}=0.003)$, and was similar between ALF and urine (Figure 2D). Glucose content in both AMF and ALF differed from that in the corresponding maternal urine sample 

$272 \mathrm{ALF}$ in $\mathrm{pH}($ Figure $2 \mathrm{C})$, erythrocyte/Hb (Figure $2 \mathrm{G})$ and bilirubin (Figure $2 \mathrm{~F})(\mathrm{P}=0.003, \mathrm{P}=$ 2730.035 and $\mathrm{P}<0.001$, respectively), while all other parameters of the Combur-Test ${ }^{\circledR}$ were

$(\mathrm{P}<0.001$ and $\mathrm{P}<0.001$, respectively; Figure 2E). Seventeen AMF and 12 ALF samples were positive for glucose, while glucosuria was present in only one dog, which was subsequently diagnosed with diabetes mellitus (DM). For ketone bodies, differences were found between maternal urine and ALF $(\mathrm{P}=0.027)$, but not between urine and AMF $(\mathrm{P}=0.074$; Figure $2 \mathrm{~F})$. Ketonuria was detected in 10 of 17 dogs with emergency C-section and 3 of 9 dogs with elective surgery. Nine bitches of small, 3 of medium and 1 of large size breed dogs were affected (Figure 2F). Bilirubin content of maternal urine was different from AMF $(\mathrm{P}=0.01)$ but similar to ALF $(P=0.131$; Figure $2 \mathrm{G})$. Only one urine sample tested positive for nitrite, and UBG was normal in all fluids (not shown).

The Total Hardness Test revealed that fetal fluid samples had more often high $\mathrm{Ca} / \mathrm{Mg}$ content $(n=19$ of AMF and $n=21$ of ALF) than maternal urine $(n=9)(P=0.001$ and $P<0.001$, respectively; Figure 3).

The AmniSure ${ }^{\circledR}$ Test was performed on AMF, ALF and maternal urine from 15 dogs (including $3 \mathrm{AMF}$ and $2 \mathrm{ALF}$ with macroscopic blood contamination). All AmniSure ${ }^{\circledR}$ Tests were valid (i.e. the control line was always present) and all samples were negative for PAMG1. Based on these results, no further testing was carried out on additional animals.

Sensitivity and specificity for SG and for the detection of leukocytes, protein, glucose, Hb, $\mathrm{Ca} / \mathrm{Mg}$ and glucose without ketones in urine and fetal fluids was between $42-100 \%$ and 65 $100 \%$, respectively (Table 3). Best likelihood ratios were found for SG and for the combination of glucose without ketone bodies (Table 3).

\subsection{Amniotic fluid compared to allantoic fluid}

Specific gravity of AMF was lower than ALF $(\mathrm{P}<0.001$; Figure 1$)$ and there was no correlation between the two $(\mathrm{P}=0.292)$. There were significant differences between AMF and 
274 similar $(\mathrm{P} \geq 0.516)$. The Total Hardness Test showed no difference between the two fluid 275 types (Figure 3).

277 4. Discussion

278 Using rapid semi-quantitative tests we determined that fetal fluids have a SG between 1.005 279 and 1.022, a pH of 5-9, and may contain leukocytes, protein, glucose, ketone bodies, 280 erythrocyte/ $\mathrm{Hb}$ and $\mathrm{Ca} / \mathrm{Mg}$. However, more interesting is that we found differences in 281 biochemical composition between fetal fluids and maternal urine, which may help to 282 recognize rupture of the fetal membranes in dogs. While in humans a non-invasive test based 283 on the detection of amniotic fluid PAMG-1 can be used for the clinical diagnosis of premature 284 fetal membrane rupture [8, 9], this test was not diagnostic in our study in dogs. The 285 AmniSure $^{\circledR}$ Test was negative not only in urine but in all fetal fluid samples regardless of 286 macroscopic blood contamination. Therefore, we speculate that in dogs there is either no 287 protein in fetal fluids homologue to the human PAMG-1 or, more likely, that the antibody 288 used in the human assay does not cross-react with the canine protein. These assumptions 289 require further investigation.

290 Although we did not find a single test parameter which is unique for fetal fluids in dogs, 291 based on the best negative likelihood ratio, a SG $>1.022$ is a clear indicator of maternal urine.

292 However, lower values can also be found in bitches with hypo-, isosthenuria and minimally 293 concentrated urine ( $\mathrm{SG}<1.008,1.008-1.012$ and 1.013-1.030, respectively) [28] and, 294 therefore, are not diagnostic. The high variability in urine SG observed in our study may have 295 been the consequence of intravenous fluid administration before and during surgery. 296 Interestingly, the range of SG values in AMF and ALF was less variable, which suggests that 297 their production is tightly regulated through various mechanisms $[11-18,20]$ and does not 298 respond so quickly to sudden changes in maternal fluid homeostasis. Because all urine 299 samples were collected during surgery after the bitches had received intravenous fluid 300 infusion, the overlap in SG between maternal urine and AMF or ALF may have been greater 
301 in this study than it would be during a natural whelping when intravenous fluids are not

302 administered.

303 Whereas high SG could be used to rule out the presence of fetal fluids, the presence of 304 glucose was highly suspicious for AMF and ALF, as glucosuria should not occur in healthy 305 adult dogs [28]. Glucose in the absence of ketone bodies in the fluid samples further increased 306 the likelihood of positively identifying fetal fluids. If we used that as a marker for AMF and 307 ALF in our data set, all urine samples would have been correctly ruled out, but fetal fluids 308 would have been identified in only 16 dogs. While glucose measured with the Combur-Test ${ }^{\circledR}$ 309 was detected in several AMF and ALF samples, it was present in only one maternal urine 310 sample. This bitch's urine was also positive for ketones. We confirmed that she had diabetes 311 mellitus (DM), which is very uncommon despite the substantial decrease in whole body 312 insulin sensitivity in late canine pregnancy [29-31]. Ketonuria without glucosuria, on the 313 other hand, is common in pregnant dogs due to the pregnancy toxemia and/or anorexia that 314 may precede parturition [31, 32]. This was also observed in 12 of the 26 bitches analyzed, 315 especially in small size dogs. In some cases, ketonuria was also detected together with a 316 positive ketone test in fetal fluids, which is consistent with increased maternal and/or fetal fat 317 mobilization and subsequent ketone production in the affected dogs.

318 Protein content in the fetal fluids measured with the Combur ${ }^{\circledR}$-Test was higher than in 319 maternal urine. This is not surprising, as normal urine in dogs contains no or only small 320 amounts of protein [28]. Proteinuria is normal in canine neonates due to the immaturity of the 321 kidneys [27] and thus fetal urine may contribute to the increased protein levels of AMF and $322 \mathrm{ALF}$. The source of the higher $\mathrm{Hb}$ content in the fetal fluids compared to urine might have 323 been the marginal hematoma (hemophagous region) of the placental girdle. Blood pooled in 324 these areas may serve as an iron source for the fetus [33-35]. However, contamination with 325 microscopic amounts of blood during sample collection also contributing to increased $\mathrm{Hb}$ and 326 protein levels cannot be completely ruled out. It may also explain the presence of leukocytes 327 in the fetal fluids, although finding them in limited numbers may be normal. Accordingly, in a 
recent study in mares, most AMF collected at birth also contained a small number of

329 polymorphonuclear leukocytes [36]. Other components of the immune system e.g. lysozyme

330 and IgG have already been identified in the fetal fluids of dogs [21] supporting the role of

331 AMF and ALF in the immunoprotection of the fetus.

332 In our study, AMF $\mathrm{pH}$ was similar among dogs, while the $\mathrm{pH}$ of ALF and especially urine

333 varied considerably. AMF $\mathrm{pH}$ was also higher than that in ALF, which is comparable to the

334 findings in sheep pregnancy during the last trimester [14]. The higher bilirubin levels we

335 found in canine maternal urine and ALF compared to AMF can be explained by the excretion

336 of bilirubin in the urine of the dam [28, 37] and the fetus, respectively, and perhaps by the

337 conversion of uteroverdin of the marginal placental hematoma into bilirubin contributing to

338 higher levels in ALF.

339 Using the Total Hardness Test we found higher $\mathrm{Ca}$ and/or Mg content in fetal AMF and ALF

340 than in maternal urine, however we were unable to differentiate between the two minerals due

341 to methodology. Their higher content in these fluid compartments may suggest that they could

342 serve as reserve pools for $\mathrm{Mg}$ and $\mathrm{Ca}$ for the developing canine fetus. Calcium is necessary

343 for bone mineralization, muscle contractions, movements as well as cell signaling and

344 enzymatic reactions within the fetus [38].

346 Intentionally, we used simple tests accepting subjectivity and limitations of interpretation 347 compared to quantitative laboratory analysis, as they should be practical for breeders and 348 veterinarians in an emergency situation. Therefore, it should be kept in mind that these semi349 quantitative tests, which were not validated for canine fetal fluids, should only be used to 350 differentiate among the fluid types and not to draw conclusions on the exact composition of 351 fetal fluids. Furthermore, the collection of fluids was performed during C-section to ensure 352 their origin and to allow clear demonstration of any differences among them. Therefore, 353 another limitation is that this approach does not take into account the potential influence of 354 vaginal secretions on the test result. To eliminate a possible confounding effect from the 
mixing of vaginal secretions to the fetal fluids, in the clinical setting, collection of mid-stream

356 vulvar discharge fluid may be recommended. We took AMF and ALF from only one fetus of

357 each bitch, which may be considered a bias factor, as it does not take into account individual

358 differences in a litter. However, we might have compromised puppy health by prolonging

359 birth if all fetuses had been sampled, especially in cases of emergency C-sections, which 360 comprised $65 \%$ of all deliveries in this study.

\section{5. Conclusions}

363 To accomplish our goal to find a test that can be easily performed and detect rupture of the 364 fetal membranes, we determined several biochemical parameters in fetal fluids and in 365 maternal urine of dogs. We found that the AmniSure ${ }^{\circledR}$ Test, which is used in humans with high 366 diagnostic accuracy, cannot identify canine AMF or ALF. Based on our results in 26 bitches 367 undergoing $\mathrm{C}$-section, the presence or absence of fetal fluids could be best determined by a 368 positive glucose test without ketone bodies or by SG higher than 1.022, respectively. These 369 tests may serve as additional tools to recognize parturition if clear-yellowish vulvar discharge 370 is present in a term pregnant bitch. However, their accuracy and practicability in the clinical 371 setting still need to be confirmed.

\section{Competing interests}

374 The authors declare that they have not received any financial compensation and have no 375 personal relationships with other people or organizations that could inappropriately bias their 376 work.

\section{Authors' contributions}

379 OB designed the study, contributed to sample collection and analysis, evaluated and 380 interpreted the data, and wrote the manuscript. MR analyzed the samples, evaluated and 381 interpreted the data, and helped draft the manuscript. SK collected the samples, contributed to 
382 interpretation of data, and critically revised the manuscript. EM contributed to study design, 383 interpretation of data and carefully revised the manuscript. IMR contributed to study design, 384 sample collection, evaluation and interpretation of data, and critically revised the manuscript. 385 All authors read and approved the final manuscript.

386

387 Acknowledgements

388 The AmniSure ${ }^{\circledR}$ Test kits were generously provided by AmniSure GmbH (Wetzlar, Germany).

389 We would like to thank Dr. Sylvia J. Bedford-Guaus for assisting with language editing. 
391

392

393

394

395

396

397

398

399

400

401

402

403

404

405

406

407

408

409

410

411

412

413

414

415

416

417

418

419

420

421

422

423

424

425

426

427

428

429

430

431

432

433

434

435

436

437

438

439

440

[1] Johnston SRK, MV.; Olson, PNS. Canine and feline theriogenology. 1 ed. Philadelphia: Saunders; 2001.

[2] Linde Forsberg C. Pregnancy diagnosis, normal pregnancy and parturition in the bitch. In: England $\mathrm{GvH}$, A., editor. BSAVA Manual of canine and feline reproduction and neonatology. Gloucester: BSAVA; 2010. p. 89-97.

[3] Darvelid AW, Linde-Forsberg C. Dystocia in the bitch: A retrospective study of 182 cases. Journal of Small Animal Practice. 1994;35:402-7.

[4] Munnich A, Kuchenmeister U. Dystocia in numbers - evidence-based parameters for intervention in the dog: causes for dystocia and treatment recommendations. Reprod Domest Anim. 2009;44 Suppl 2:141-7.

[5] Linde Forsberg C, Persson G. A survey of dystocia in the Boxer breed. Acta Vet Scand. 2007;49:8.

[6] Doret M, Cartier R, Miribel J, Massardier J, Massoud M, Bordes A, et al. Premature preterm rupture of the membrane diagnosis in early pregnancy: PAMG-1 and IGFBP-1 detection in amniotic fluid with biochemical tests. Clin Biochem. 2013;46:1816-9.

[7] Petrunin DD, Griaznova IM, Petrunina Iu A, Tatarinov Iu S. [Immunochemical identification of human placental organ specific alpha2-globulin and its concentration in amniotic fluid]. Biull Eksp Biol Med. 1976;82:803-4.

[8] Cousins LM, Smok DP, Lovett SM, Poeltler DM. AmniSure placental alpha microglobulin-1 rapid immunoassay versus standard diagnostic methods for detection of rupture of membranes. Am J Perinatol. 2005;22:317-20.

[9] Palacio M, Kuhnert M, Berger R, Larios CL, Marcellin L. Meta-analysis of studies on biochemical marker tests for the diagnosis of premature rupture of membranes: comparison of performance indexes. BMC Pregnancy Childbirth. 2014;14:183.

[10] Ramsauer B, Duwe W, Schlehe B, Pitts R, Wagner D, Wutkewicz K, et al. Effect of blood on ROM diagnosis accuracy of PAMG-1 and IGFBP-1 detecting rapid tests. J Perinat Med. 2015;43:417-22.

[11] Bor NM, Karpuzoglu T, Hamzadi T, Edguer E, Kis M. Role of fetal skin in circulation of amniotic fluid. Arch Int Physiol Biochim. 1970;78:69-78.

[12] Brace RA. Progress toward understanding the regulation of amniotic fluid volume: water and solute fluxes in and through the fetal membranes. Placenta. 1995;16:1-18.

[13] Li N, Wells DN, Peterson AJ, Lee RS. Perturbations in the biochemical composition of fetal fluids are apparent in surviving bovine somatic cell nuclear transfer pregnancies in the first half of gestation. Biol Reprod. 2005;73:139-48.

[14] Mellor DJ, Slater JS. Daily changes in amniotic and allantoic fluid during the last three months of pregnancy in conscious, unstressed ewes, with catheters in their foetal fluid sacs. J Physiol. 1971;217:573-604.

[15] Mellor DJ, Slater JS. Daily changes in foetal urine and relationships with amniotic and allantoic fluid and maternal plasma during the last two months of pregnancy in conscious, unstressed ewes with chronically implanted catheters. J Physiol. 1972;227:503-25.

[16] Ross MG, Nijland MJ. Fetal swallowing: relation to amniotic fluid regulation. Clin Obstet Gynecol. 1997;40:352-65.

[17] Underwood MA, Gilbert WM, Sherman MP. Amniotic fluid: not just fetal urine anymore. J Perinatol. 2005;25:341-8.

[18] Wintour EM, Alcorn D, McFarlane A, Moritz K, Potocnik SJ, Tangalakis K. Effect of maternal glucocorticoid treatment on fetal fluids in sheep at 0.4 gestation. Am J Physiol. 1994;266:R1174-81.

[19] Fresno L, Rodriguez-Gil JE, Rigau T, Pastor J, Rivera del Alamo MM. Modulation of the biochemical composition of amniotic and allantoic fluids as a control mechanism of feline foetal development. Placenta. 2012;33:522-7. 
[20] Aralla M, Mobasheri A, Groppetti D, Cremonesi F, Arrighi S. Expression of aquaporin water channels in canine fetal adnexa in respect to the regulation of amniotic fluid production and absorption. Placenta. 2012;33:502-10.

[21] Dall'Ara P, Meloni T, Rota A, Servida F, Filipe J, Veronesi MC. Immunoglobulins G and lysozyme concentrations in canine fetal fluids at term of pregnancy. Theriogenology. 2015;83:766-71.

[22] Meloni T, Comin A, Rota A, Peric T, Contri A, Veronesi MC. IGF-I and NEFA concentrations in fetal fluids of term pregnancy dogs. Theriogenology. 2014;81:1307-11.

[23] Groppetti D, Martino PA, Ravasio G, Bronzo V, Pecile A. Prognostic potential of amniotic fluid analysis at birth on canine neonatal outcomes. Vet J. 2015;206:423-5.

[24] Bouchard GF, Solorzano N, Concannon PW, Youngquist RS, Bierschwal CJ. Determination of ovulation time in bitches based on teasing, vaginal cytology, and elisa for progesterone. Theriogenology. 1991;35:603-11.

[25] Concannon PW, Butler WR, Hansel W, Knight PJ, Hamilton JM. Parturition and lactation in the bitch: serum progesterone, cortisol and prolactin. Biol Reprod. 1978;19:1113-8.

[26] Lopate C. Estimation of gestational age and assessment of canine fetal maturation using radiology and ultrasonography: a review. Theriogenology. 2008;70:397-402.

[27] Peterson MK, MA. Small animal pediatrics: the first 12 months of life. 1 ed. St. Louis: Elsevier Saunders; 2011.

[28] Nelson RC, C. Small Animal Internal Medicine. 5 ed. St. Louis: Elsevier; 2013.

[29] Concannon PW. Canine pregnancy and parturition. Vet Clin North Am Small Anim Pract. 1986;16:453-75.

[30] Connolly CC, Papa T, Smith MS, Lacy DB, Williams PE, Moore MC. Hepatic and muscle insulin action during late pregnancy in the dog. Am J Physiol Regul Integr Comp Physiol. 2007;292:R447-52.

[31] Johnson CA. Glucose homeostasis during canine pregnancy: Insulin resistance, ketosis, and hypoglycemia. Theriogenology. 2008;70:1418-23.

[32] Root Kustritz MV. Pregnancy diagnosis and abnormalities of pregnancy in the dog. Theriogenology. 2005;64:755-65.

[33] Leiser R, Koob B. Development and characteristics of placentation in a carnivore, the domestic cat. J Exp Zool. 1993;266:642-56.

[34] Miglino MA, Ambrosio CE, dos Santos Martins D, Wenceslau CV, Pfarrer C, Leiser R. The carnivore pregnancy: the development of the embryo and fetal membranes. Theriogenology. 2006;66:1699-702.

[35] Enders AC, Carter AM. The evolving placenta: convergent evolution of variations in the endotheliochorial relationship. Placenta. 2012;33:319-26.

[36] Hemberg E, Einarsson S, Kutvolgyi G, Lundeheim N, Bagge E, Baverud V, et al. Occurrence of bacteria and polymorphonuclear leukocytes in fetal compartments at parturition; relationships with foal and mare health in the peripartum period. Theriogenology. 2015;84:163-9.

[37] Reine NJ, Langston CE. Urinalysis interpretation: how to squeeze out the maximum information from a small sample. Clin Tech Small Anim Pract. 2005;20:2-10.

[38] Lafond J, Goyer-O'Reilly I, Laramee M, Simoneau L. Hormonal regulation and implication of cell signaling in calcium transfer by placenta. Endocrine. 2001;14:285-94. 
Table 1

\begin{tabular}{|c|c|c|c|c|c|}
\hline Combur-Test $^{\circledR}$ & \multicolumn{5}{|c|}{ Values corresponding to the color scale of the test strip } \\
\hline $\begin{array}{c}\text { Leukocytes } \\
\text { (Leu) }\end{array}$ & negative & $\begin{array}{c}1+ \\
(\sim 10-25 \mathrm{Leu} / \mu \mathrm{L})\end{array}$ & $\begin{array}{c}2+ \\
(\sim 75 \mathrm{Leu} / \mu \mathrm{L})\end{array}$ & $\begin{array}{c}3+ \\
(\sim 500 \mathrm{Leu} / \mu \mathrm{L})\end{array}$ & \\
\hline Nitrite & negative & positive & & & \\
\hline pH & 5 & 6 & 7 & 8 & 9 \\
\hline Protein & negative & $\begin{array}{c}1+ \\
(0.3 \mathrm{~g} / \mathrm{L})\end{array}$ & $\begin{array}{c}2+ \\
(1 \mathrm{~g} / \mathrm{L})\end{array}$ & $\begin{array}{c}3+ \\
(5 \mathrm{~g} / \mathrm{L})\end{array}$ & \\
\hline Glucose & normal & $\begin{array}{c}1+ \\
(2.8 \mathrm{mmol} / \mathrm{L})\end{array}$ & $\begin{array}{c}2+ \\
(5.5 \mathrm{mmol} / \mathrm{L})\end{array}$ & $\begin{array}{c}3+ \\
(17 \mathrm{mmol} / \mathrm{L})\end{array}$ & $\begin{array}{c}4+ \\
(55 \mathrm{mmol} / \mathrm{L})\end{array}$ \\
\hline Ketones & negative & $\begin{array}{c}1+ \\
(1 \mathrm{mmol} / \mathrm{L})\end{array}$ & $\begin{array}{c}2+ \\
(5 \mathrm{mmol} / \mathrm{L})\end{array}$ & $\begin{array}{c}3+ \\
(15 \mathrm{mmol} / \mathrm{L})\end{array}$ & \\
\hline Urobilinogen & normal & $\begin{array}{c}1+ \\
(17 \mu \mathrm{mol} / \mathrm{L})\end{array}$ & $\begin{array}{c}2+ \\
(70 \mu \mathrm{mol} / \mathrm{L})\end{array}$ & $\begin{array}{c}3+ \\
(140 \mu \mathrm{mol} / \mathrm{L})\end{array}$ & $\begin{array}{c}4+ \\
(200 \mu \mathrm{mol} / \mathrm{L}) \\
\end{array}$ \\
\hline Bilirubin & negative & $1+$ & $2+$ & $3+$ & \\
\hline $\begin{array}{l}\text { Erythrocyte } \\
\text { (Ery) }\end{array}$ & negative & $\begin{array}{c}1+ \\
(\sim 5-10 \text { Ery } / \mu \mathrm{L})\end{array}$ & $\begin{array}{c}2+ \\
(\sim 25 \mathrm{Ery} / \mu \mathrm{L})\end{array}$ & $\begin{array}{c}3+ \\
(\sim 50 \mathrm{Ery} / \mu \mathrm{L})\end{array}$ & $\begin{array}{c}4+ \\
(\sim 250 \mathrm{Ery} / \mu \mathrm{L})\end{array}$ \\
\hline $\begin{array}{l}\text { Hemoglobin } \\
\text { (Hb) }\end{array}$ & negative & $\begin{array}{c}1+ \\
(\sim 10 \mathrm{Ery} / \mu \mathrm{L})\end{array}$ & $\begin{array}{c}2+ \\
(\sim 25 \mathrm{Ery} / \mu \mathrm{L})\end{array}$ & $\begin{array}{c}3+ \\
(\sim 50 \mathrm{Ery} / \mu \mathrm{L})\end{array}$ & $\begin{array}{c}4+ \\
(\sim 250 \mathrm{Ery} / \mu \mathrm{L})\end{array}$ \\
\hline
\end{tabular}

488 Color scale values of the Combur-Test ${ }^{\circledR}$ are shown for each parameter as indicated on the 489 label. 


\begin{tabular}{ccccccccc}
\hline Bitch & $\mathbf{N}$ & $\begin{array}{c}\text { BW } \\
\mathbf{( k g})\end{array}$ & $\begin{array}{c}\text { Age } \\
\text { (years) }\end{array}$ & $\begin{array}{c}\text { Primi- } \\
\text { /Pluriparous } \\
(\mathbf{N} / \mathbf{N})\end{array}$ & $\begin{array}{c}\text { Elective/ } \\
\text { Emergency } \\
\text { C-section } \\
\text { (N/N) }\end{array}$ & $\begin{array}{c}\text { Litter } \\
\text { size }\end{array}$ & $\begin{array}{c}\text { Pup birth } \\
\text { weight } \\
(\mathbf{g})\end{array}$ & $\begin{array}{c}\text { Male/Female } \\
\text { pup } \\
(\mathbf{N} / \mathbf{N})\end{array}$ \\
\hline $\begin{array}{c}\text { Large/Giant } \\
(>\mathbf{3 0 k g})\end{array}$ & 6 & $43.1 \pm 12.4$ & $5.3 \pm 1.8$ & $3 / 3$ & $2 / 4$ & $5.3 \pm 3.0$ & $463 \pm 156$ & $3 / 3$ \\
\hline $\begin{array}{c}\text { Medium } \\
(\mathbf{1 0 - 3 0 k g )}\end{array}$ & 7 & $19.2 \pm 5.4$ & $4.4 \pm 2.0$ & $3 / 4$ & $1 / 6$ & $3.9 \pm 3.4$ & $376 \pm 65$ & $5 / 2$ \\
\hline $\begin{array}{c}\text { Small } \\
(<\mathbf{1 0} \mathbf{~ k g})\end{array}$ & 13 & $4.8 \pm 2.1$ & $2.5 \pm 2.0$ & $11 / 2$ & $6 / 7$ & $3.4 \pm 1.8$ & $\begin{array}{c}153 \pm 51 \\
(\mathrm{~N}=12)\end{array}$ & $\begin{array}{c}5 / 7 \\
(\mathrm{~N}=12)\end{array}$ \\
\hline
\end{tabular}

491 Body weight (BW), age, parity, type of C-section and litter size of the bitches included in the

492 study ( $\mathrm{n}=26)$. Birth weight and gender of the puppies from which fetal fluids were collected

493 are shown (available from $\mathrm{n}=25$ ). Data are presented as mean \pm standard deviation. $\mathrm{N}$ : number 494 of animals 
Table 3

\begin{tabular}{|c|c|c|c|c|c|c|c|c|}
\hline Threshold & $\begin{array}{l}\text { TN } \\
\text { (N) }\end{array}$ & $\begin{array}{l}\text { FP } \\
\text { (N) }\end{array}$ & $\begin{array}{l}\text { TP } \\
(\mathbf{N})\end{array}$ & $\begin{array}{l}\text { FN } \\
\text { (N) }\end{array}$ & $\begin{array}{c}\text { Sensitivity } \\
(\%)\end{array}$ & $\begin{array}{c}\text { Specificity } \\
(\%)\end{array}$ & $\begin{array}{c}\text { Positive } \\
\text { LR }\end{array}$ & $\begin{array}{c}\text { Negative } \\
\text { LR }\end{array}$ \\
\hline $\mathrm{SG} \leq 1.022$ & 17 & 9 & 26 & 0 & 100 & 65 & 2.9 & 0 \\
\hline Leukocyte $>0$ & 25 & 1 & 11 & 15 & 42 & 96 & 11 & 0.6 \\
\hline Glucose $>\mathbf{0}$ & 25 & 1 & 18 & 8 & 69 & 96 & 18 & 0.3 \\
\hline Protein $>1+$ & 25 & 1 & 12 & 14 & 46 & 96 & 12 & 0.6 \\
\hline $\mathrm{Hb}>2.5^{+}$ & 24 & 2 & 22 & 4 & 85 & 92 & 11 & 0.2 \\
\hline $\mathrm{Ca} / \mathrm{Mg}>3.5+$ & 17 & 9 & 22 & 4 & 85 & 65 & 2.4 & 0.2 \\
\hline $\begin{array}{c}\text { Glucose }>0 \\
\text { and no ketone } \\
\text { bodies }\end{array}$ & 26 & 0 & 16 & 10 & 62 & 100 & 61.5 & 0.4 \\
\hline
\end{tabular}

496 Sensitivity, specificity, positive likelihood ratio and negative likelihood ratio of those

497 parameters, where significant differences between maternal urine and both fetal fluids were 498 found. The threshold for each parameter was set at the same cut-off value that was used in the 499 Fisher's exact test and $\leq 1.022$ for SG. TN: true negative, FP: false positive, TP: true positive, 500 FN: false negative, LR: likelihood ratio, N: number of samples; SG: specific gravity; Hb: 501 erythrocyte/hemoglobin; $\mathrm{Ca} / \mathrm{Mg}$ : combined calcium and magnesium content 
503 Figure 1 Specific gravity of the fetal fluids and maternal urine in each individual animal

504 Dogs included in the study are presented on the $\mathrm{X}$ axis from number 1 to 26 . Number 1-6 are 505 the large/giant size $(>30 \mathrm{~kg})$ bitches, number $7-13$ are the medium $(10-30 \mathrm{~kg})$ and $14-26$ are 506 the small size $(<10 \mathrm{~kg})$ dogs. No. 13 is the bitch with diabetes mellitus. Maternal urine is 507 marked with blue, amniotic fluid (AMF) with red and allantoic fluid (ALF) with green.

Figure 2 Combur-Test ${ }^{\circledR}$ parameters measured in the fetal fluids and in maternal urine 510 in each individual animal

A: Leukocytes; B: Erythrocyte/hemoglobin C: Protein; D: pH; E: Glucose; F: Ketones; G: Bilirubin. Dogs included in the study are presented on the $\mathrm{X}$ axis from number 1 to 26 .

513 Number 1-6 are the large/giant size ( $>30 \mathrm{~kg})$ bitches, number 7-13 are the medium $(10-30 \mathrm{~kg})$ 514 and 14-26 are the small size $(<10 \mathrm{~kg})$ dogs. No. 13 is the bitch with diabetes mellitus. 515 Maternal urine is marked with blue, amniotic fluid (AMF) with red and allantoic fluid (ALF) 516 with green.

518 Figure 3 Combined calcium and magnesium content of the fetal fluids and maternal 519 urine in each individual animal

520 Dogs included in the study are presented on the $\mathrm{X}$ axis from number 1 to 26 . Number 1-6 are 521 the large/giant size $(>30 \mathrm{~kg})$ bitches, number 7-13 are the medium $(10-30 \mathrm{~kg})$ and $14-26$ are 522 the small size $(<10 \mathrm{~kg})$ dogs. No. 13 is the bitch with diabetes mellitus. Maternal urine is 523 marked with blue, amniotic fluid (AMF) with red and allantoic fluid (ALF) with green. 